\title{
An Application of a Vulnerability Index \\ to 0il Spill Modeling in the Gulf of Mexico
}

\section{By}

Robert P. LaBelle, Gail Rainey,*

and Kenneth J. Lanfear

\author{
U.S. Geological Survey \\ *Minerals Management Service \\ Open-File Report 82-804
}

May 1982 


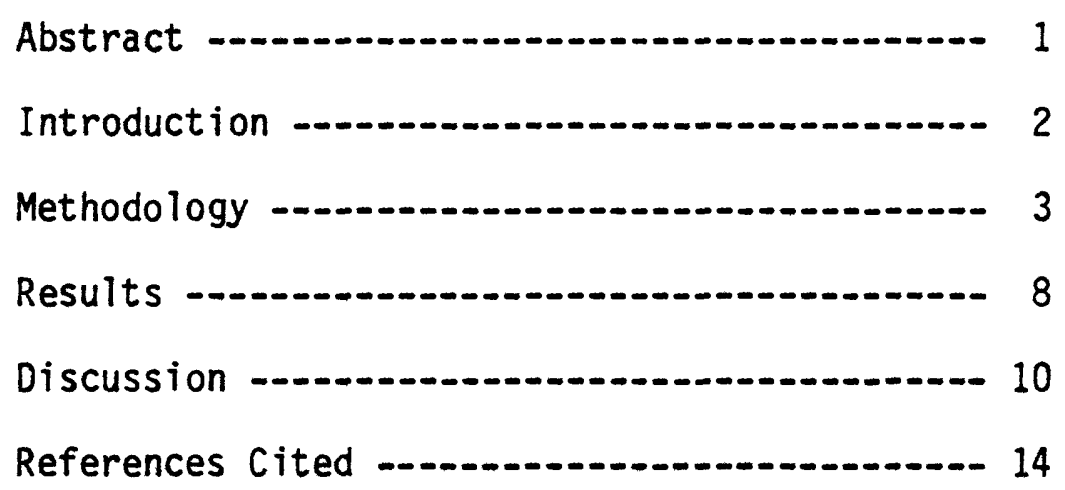




\section{List of Figures}

Figure

Page

1. Map showing the subdivisions of the Gulf of Mexico

into hypothetical spill launching areas. -................- 5

2. Map showing the division of the Gulf of Mexico coastline into 43 segments (representing county/

parish boundaries).

3. Relative impact to land segments as calculated by combining segment vulnerabilities with oil spill contact probabilities.

4. Relative risk (by quartile) that potential oil spill areas present to land, weighted by specific land segment vulnerabilities. 
An Application of a Vulnerability Index

to Oil Spill Modeling in the Gulf of Mexico

By Robert P. LaBelle, Gail Rainey, and Kenneth J. Lanfear

\begin{abstract}
An analysis was made of the relative impact to the shoreline of the Gulf of Mexico from proposed Federal Outer Continental Shelf oil and gas leasing activity. An oil spill trajectory model was coupled with a land segment vulnerability characterization to predict the risks to the shoreline. Such a technique allows spatial and temporal variability in oil spill sensitivity to be represented and combined with the likelihood of oil spill contact to specific coastal segments in the study area. Predicted relative impact was greatest along the coastlines of Louisiana, Mississippi, and Alabama. Useful information is provided for environmental impact analysis, as well as oil spill response planning.
\end{abstract}




\section{Introduction}

0il spill modeling is a valuable tool which has been used to assess the risks to the coastline from proposed drilling and oil production activity on the Outer Continental Shelf (OCS). Although such modeling efforts provide information on the likelihood of hypothetical "spills" contacting certain areas of the coastline, it is difficult to determine the level of impact such contacts entail. In order to characterize specific coastal segments, it is necessary to define the sensitivity of -an area by estimating its vulnerability to spilled oil. The concept of oil spill vulnerability indexing was developed by Gundlach and Hayes (1978), who ranked shoreline types on the basis of the physical longevity of oil in each environment and biological considerations. The present study will combine a vulnerability index of the Gulf of Mexico's coastline, developed by the Minerals Management Service (MMS), U.S. Department of Interior, with the results of an oil spill risk analysis in order to better assess the long-term impacts to the coast due to proposed OCS oil and gas related activities. Factors which define vulnerability in this study include: shoreline energy level, human use of the area, cleanup impacts, important species present, and habitat recovery to pre-spill levels.

In addition to environmental impact assessment, the use of vulnerability indexing and oil spill trajectory modeling provides quantitative input to decision making regarding oil spill contingency planning. For example, the U.S. Coast Guard (USCG) and the National Oceanic and Atmospheric Administration (NOAA) developed an oil spill mitigation plan for the Ixtoc I blowout in which 
an environmental sensitivity index was assigned to each coastal area along the spill's forecasted trajectory (OSIR, 1982). The USCG used this data, along with tidal current information, to decide where to deploy containment booms in order to protect the Texas coastline. Shoreline countermeasures must take into account limited cleanup resources; since it may be impossible to protect the entire coastline threatened from a major accident. Time limitations make it necessary to have immediate access to information concerning not only where the spill is likely to come ashore, but also the relative sensitivity of the land segments exposed. In this way, spill response teams may focus their efforts on the most sensitive areas at risk.

\section{Methodology}

The U.S. Geological Survey's (USGS) 0il Spill Trajectory Analysis (OSTA) model was used to estimate the probability of oil spills (of 1,000 barrels or greater) occurring and contacting coastal segeents. The model considers the probability of spill occurrences based on historical trends, the likely movement of oil slicks based on a climatological model, and the locations of major environmental resources which could be vulnerable to spilled oil. A description of the OSTA model used in this analysis can be found in previous papers (Lanfear et. al., 1979; Smith et. al, 1982; Lanfear and Samue1s, 1981).

An OSTA model was run for the Gulf of Mexico OCS Federal lease area (LaBelle, 1982). The study had the objective of determining relative risks associated with oil and gas production and transportation in the 
western, central, and eastern Gulf, to aid in the analysis of tracts to be offered by MMS for lease. In figure 1, the study area is shown divided into three planning areas, each containing subareas from which hypothetical spills were launched. These "spill launch areas" each represent a possible location of large numbers of tracts to be offered in future ocs leasing activities, and were selected for comparative analys is purposes. Figure 2 shows the coastline divided into 43 coastal segments representing county/ parish boundaries. Probabilities of oil spill contacts to these coastal segments were calculated by simulating in Monte Carlo fashion a large number of hypothetical oil spills from each of the launch areas. In the model, each spill was transported by seasonal surface-water velocity fields (Blumberg and Mellor, 1981) and by winds sampled from wind transition matrices calculated from U.S. Weather Service records. Spill movement was determined by the vector sum of a surface-water velocity field plus the surface drift caused by wind (drift factor of 0.035 with a variable drift angle ranging from 0 to $25^{\circ}$ clockwise, according to Samuels et. al., 1982).

The OSTA model calculates risks on the basis of the volume of oil resources estimated to be present in an area. The estimated oil resources used for oil spill risk calculations in this study correspond to those used by MMS in preparing the Regional Environmental Impact Statement for the Gulf of Mexico OCS lease area. Both the production and transportation of OCS oil are taken into account when calculating risks. Based on a total development/production scenario in which 5.6 billion barrels of oil are estimated to be found and produced over a production life of 40 years 


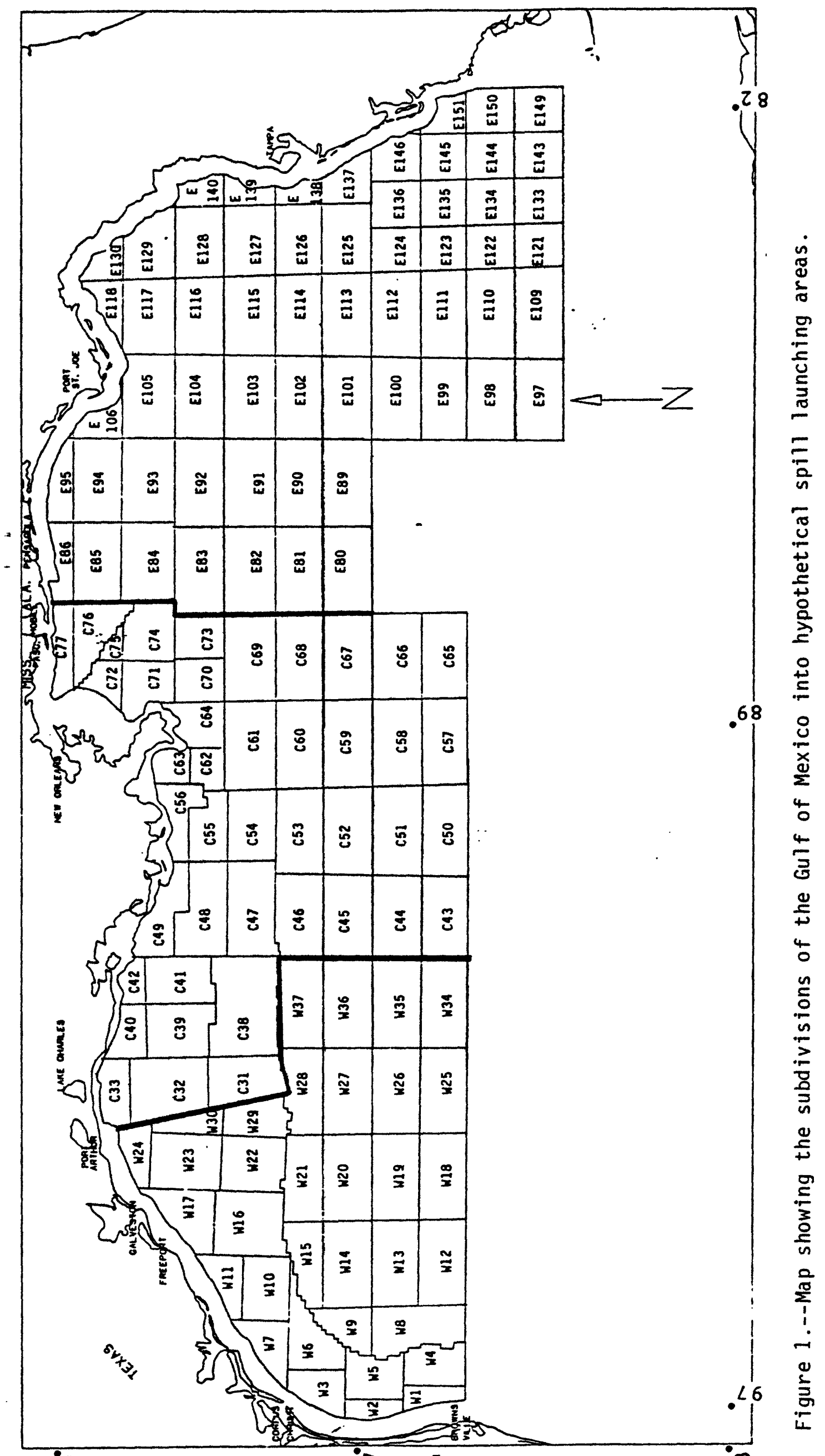




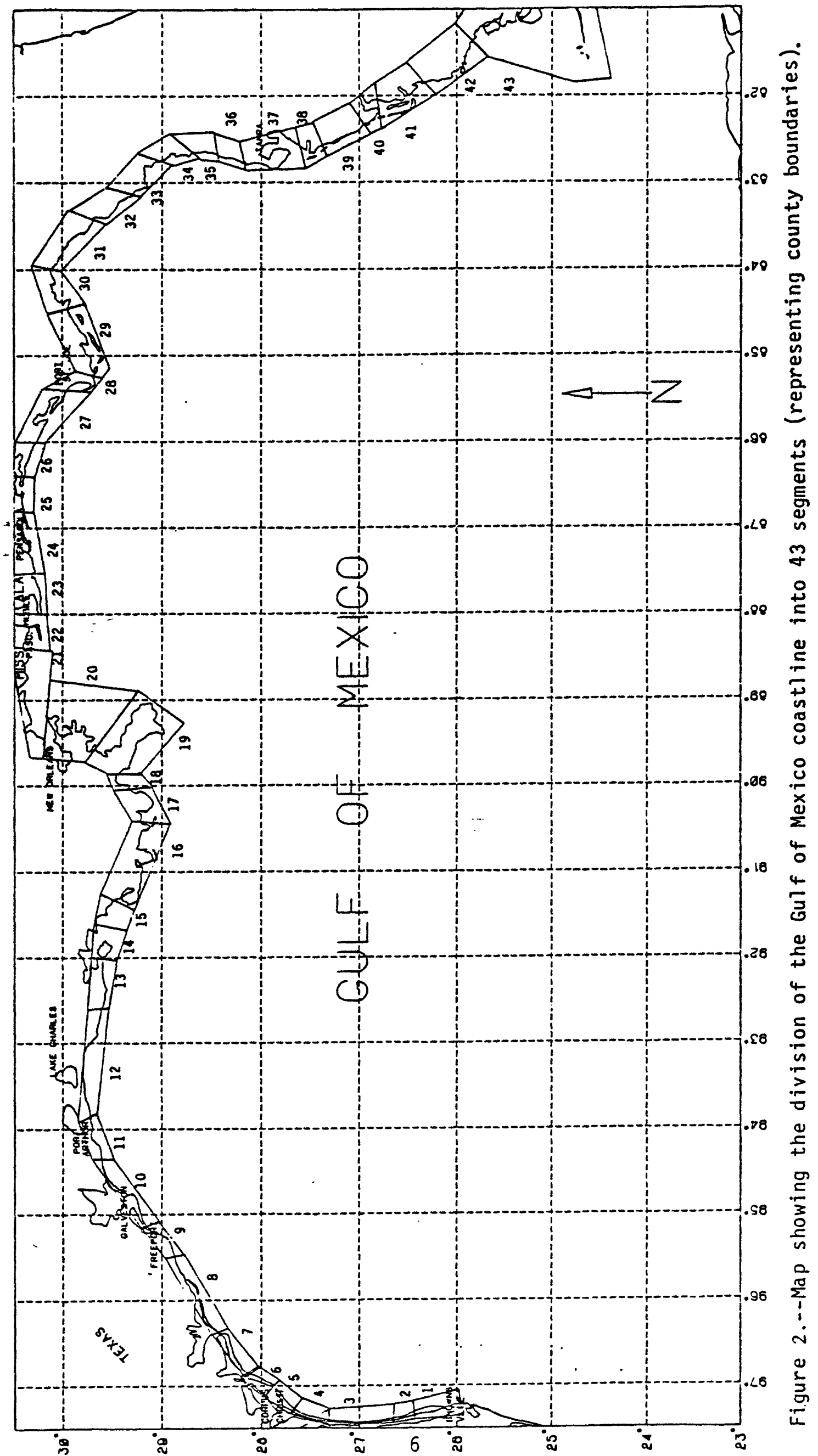


in the Gulf of Mexico (LaBelle, 1982), the expected number of spills (of 1,000 barrels or greater) occurring and contacting each land segment within a 10 day travel time was calculated.

The expected number of spills contacting each coastal segment was then weighted by the cumulative number of oil-sensitive coastal resources present in that segment, as determined by a Gulf coastal resource inventory tabulated by county/parish. Taking into account the fact that a major line of defense of cleanup response is to close off inlets, and assuming that, if an oil spill should occur, effective cleanup and containment countermeasures would be initiated, only those resources occurring along the exposed coastline are considered. The inventory of oil-sensitive resources was made by examining biological, geomorphological, and socioeconomic features of the coastline. Biologically significant resources included were areas of high marine productivity, high density offshore shellfish areas, seagrass beds, endangered/threatened species, and bird rookeries habitats. In surveying geomorphologic coastal types, the presence of wetlands in a segment was counted as an oil-sensitive resource. Gundlach and Hayes (1978) rank marshes and mangroves as the most sensitive coastal types, based on shoreline interaction with the physical and geomorphologic processes controlling oil disposition, observed persistence of oil, and habitat recovery.

Possible spill impact on man's use of resources was accounted for by the inclusion of three socioeconomic features: the presence in a segment of major shorefront recreational beaches, designated environmental preservation 
areas, or archaeological sites. The assumption is made that all selected resources are equally important for purposes of this analysis. The distribution of resources within a given segment need not be determined, since the oil spill model assumes any contact to a segment affects the entire segment because of implied slick spreading.

Results

An overall characterization of the potential impact to coastal land segments in the Gulf of Mexico from the OCS leasing total development/ production scenario is presented in figure 3. The relative ranking of segments was determined by combining the mean number of spills expected to occur and contact the segment over the 40-year production life of the study area with the specific vulnerability score of each land segment, as determined by the number of oil-sensitive coastal resources present in that segment. Thus, not only is the likelihood of contact established for each county, but also the sensitivity of the coastal segment is taken into account. Figure 3 may be used to both estimate environmental impact and to help determine optimal locations for spill response resources.

Another use of the combination of trajectory modeling and coastal vulnerability characterization is to help determine which tracts pose the most (or least) risk to the coastline. In the Gulf of Mexico, all spill launch areas (which represent proposed tracts) were scored as follows:

$$
R_{i}=\sum_{j=1}^{43}(\lambda(10) i, j)\left(\text { vol }_{j} / \text { area }_{j}\right)\left(\text { vul }_{j}\right)
$$




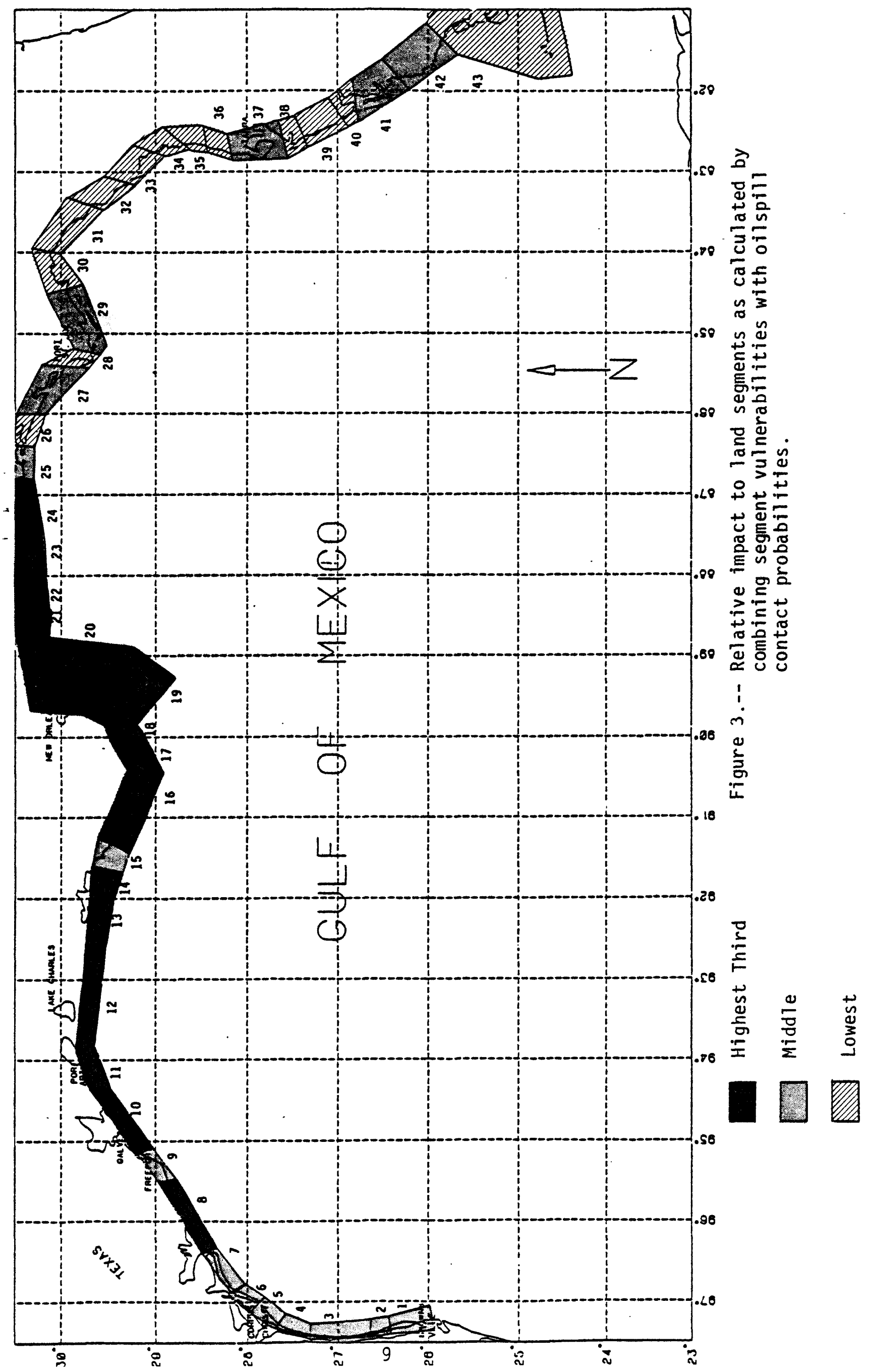


where:

$$
\begin{aligned}
R_{i}= & \text { relative risk index for launch area " } i \text { ", expressed on a "risk } \\
& \text { per acre" basis. } \\
\lambda= & \text { expected number of spills to occur and contact land segment } \\
& \text { " } j " \text { from production and transportation of oil from launch area } \\
\text { vol = } & \text { assumed volume of oil estimated to be produced from launch } \\
& \text { area " } i " \text {. } \\
\text { area }= & \text { acreage in launch area " } i \text { ". } \\
\text { vul = } & \text { vulnerability score of land segment " } j " \text { (as determined } \\
& \text { previously). }
\end{aligned}
$$

Each launch area may now be compared and ranked as to relative risk to all land segments combined. Figure 4 shows the result of ranking each launch area in order of decreasing relative risks, for the total development/production scenario in the Gulf of Mexico. This information may be used to help determine tract deletion alternatives, as well as for at-sea placement of spill cleanup equipment. It should be noted that risks due to transportation of produced oil to shore have been accounted for in the above calculations. The use of segment vulnerabilities may help in determining the best locations for bringing OCS $0 i 1$ ashore.

\section{Discussion}

The combination of oil spill trajectory modeling and shoreline vulnerability characterization has been shown to predict impacts to coastal areas in a quantitative way. Although the OSTA model is not a real-time model, but rather a long-range, probabilistic predictive tool, oil spill 


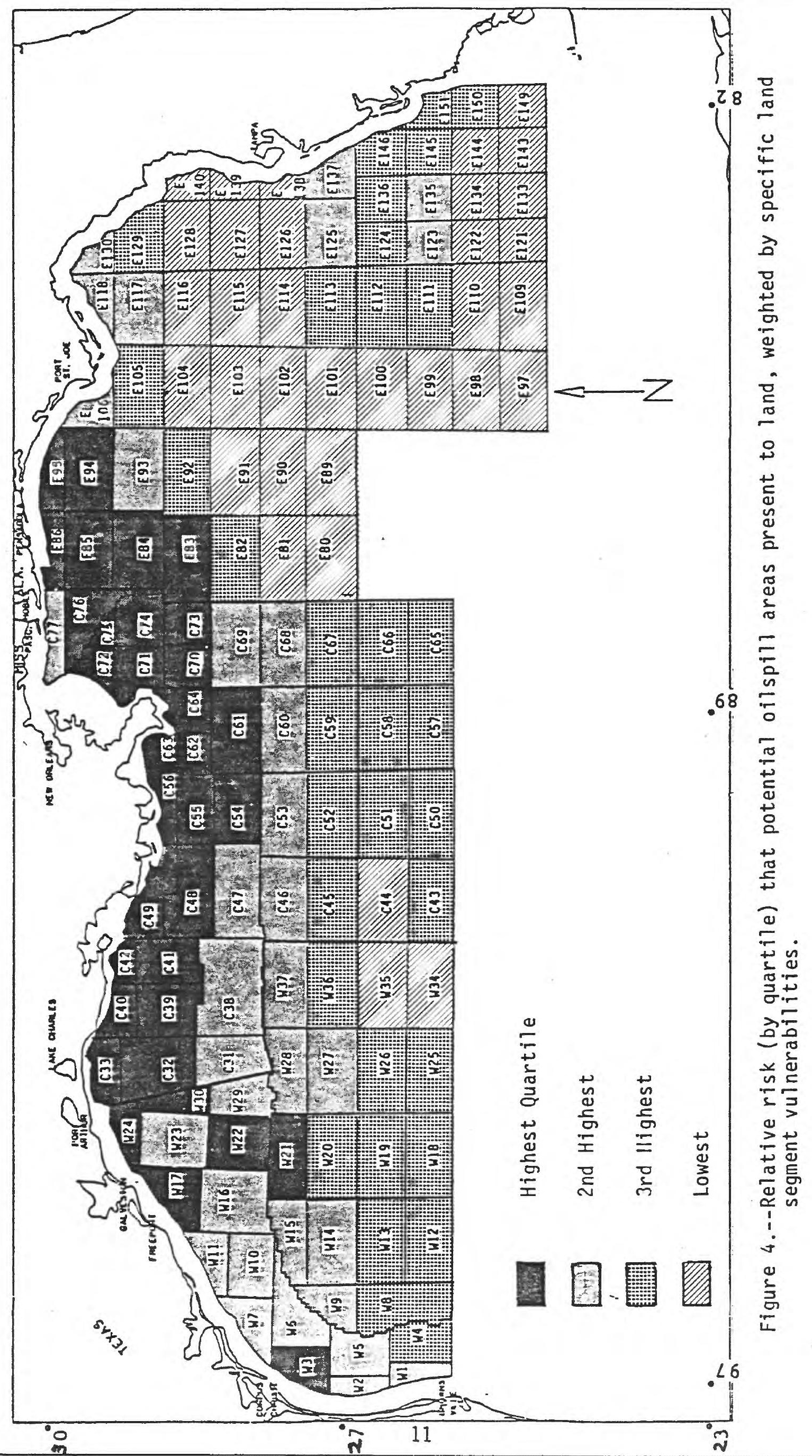


response planning may benefit from this study. Comparing shoreline segments in view of not only their oil spill sensitivity, but also their likelihood of being contacted, allows a more realistic, comprehensive evaluation of the options in contingency planning.

In this analysis, county/parish boundaries determined the extent of each coastal segment. Future studies could use the vulnerability scores of the coastline to set boundaries for such segments. However, the size of. segments should be relatively equal (about $30 \mathrm{~km}$ ) to allow for implicit assumptions in the OSTA model. Thus, the presence and sensitivity of environmental resources in an area would help to define that area for modeling purposes.

Another important consideration in the biological assessment of shoreline sensitivity is temporal variability. Due to seasonal migrations of sea birds and fish, for example, a site may be highly vulnerable for only a limited period each year. Marsh systems also may be more or less sensitive at different periods depending on the growth phase of different species of plants (Owens and Robilliard, 1981). Many vulnerability indices do not allow for temporal variation, since they are based on physical shoreline types or coastal processes. The structure of the OSTA model permits the incorporation of such temporal variations into these indices, since seasonal (or monthly) contacts are tabulated.

Combining oil spill modeling with vulnerability characterization was also shown to be of value in differentiating among proposed OCS tracts. 
The relative risk index is a single number that accounts for the net risks the tract poses to all oil-sensitive resources, and is an effective technique for identifying those tracts posing unusually high risks. The relative size of tracts should be normalized for comparative purposes, before calculating relative risks to land. 


\section{References Cited}

Blumberg, A., and Mellor, G.L., 1981, A numerical calculation of the circulation in the Gulf of Mexico: Dynalysis, Inc., Princeton, N.J., Report $66,159 \mathrm{p}$.

Gundlach, E.R., and Hayes, M.0., 1978, Vulnerability of coastal environments to oil spill impacts: Marine Technology Society Journal, V. 12, no. 4, pp. $18-27$.

LaBelle, R.P., 1982, An oil spill risk analysis for the Gulf of Mexico Outer Continental Shelf lease area regional Environmental Impact Statement: U.S. Geological Survey Open-File Report 82-238, 210 p.

Lanfear, K.J., Smith, R.A., and Slack, J.R., 1979, An introduction to the oil spill risk analysis model: Proceedings of the Offshore Technology

- Conference, 11th, Houston, Tex., 1979, OTC 3607, p. 2175.

Lanfear, K.J., and Samuels, W.B., 1981, Documentation and user's guide to the U.S. Geological Survey oil spill risk analysis model: 0ilspill trajectories and the calculation of conditional probabilities: U.S. Geological Survey Open-File Report 81-316, 95 p.

OSIR, 1982, 0 il Spill Intelligence Report, V. 5, no. 17, April 23, 1982.

Owens, E.H., and Robilliard, G.A., 1981, Shoreline sensitivity and oil spills - a re-evaluation for the 1980's: Marine Pollution Bulletin, v. 12 , no. 3 , pp. $75-78$.

Samuel S, W.B., Huang, N.E., and Amstutz, D.E., 1982, Sensitivity of an oil spill trajectory analysis model to variation in wind deflection angle: Ocean Engineering, in press.

Smith, R.A., Slack, J.R., Wyant, T., and Lanfear, K.J., 1982, The oil spill risk analysis model of the U.S. Geological Survey: U.S. Geological Survey Professional Paper 1227, 40 p. 